\author{
Jamshid Ahmadi* \\ Substance Abuse Research Center, Dual Diagnosis \\ Ward, Shiraz University of Medical Sciences, Shiraz; \\ Iran \\ Dates: Received: 15 February, 2016; Accepted: 04 \\ March, 2016; Published: 08 March, 2016 \\ *Corresponding author: Jamshid Ahmadi, Professor \\ and Founding Director, Substance Abuse Research \\ Center, Shiraz University of Medical Sciences, \\ Shiraz, Iran. Tel \& Fax: +98-71-3627 93 19; E-mail: \\ Jamshid_Ahmadi@yahoo.com \\ www.peertechz.com \\ ISSN: 2455-3484
}

Keywords: Methamphetamine related disorders Buprenorphine; Single dose

\section{Research Article \\ Fast Treatment of Methamphetamine Related Anxiety and Depressive Disorders: A Novel Approach}

\begin{abstract}
Background: Methamphetamine abuse and dependence is currently a considerable problem.

Objective: To explain the efficacy of buprenorphine in the quick management of methamphetamine related anxiety and depressive disorders and also methamphetamine withdrawal craving.

Results: $52 \mathrm{mg}$ of buprenorphine is very valuable in the treatment of severe methamphetamine related anxiety and depression and also methamphetamine craving.

Discussion: This study lightens that high dose of buprenorphine is quite effective in the lowering of anxiety, depression, and chest pain and methamphetamine withdrawal symptoms. Hence, our finding is a substantial addition to the literature.

Conclusions: We resulted that a single high dose of buprenorphine could quickly subside methamphetamine induced anxiety, depression, psychogenic pain and withdrawal symptoms.

It looks that buprenorphine may be a safe and valuable drug for the treatment of the majority of methamphetamine associated disorders.
\end{abstract}

\section{Introduction}

Buprenorphine as a partial mu receptor agonist has been under intensive study for the management of opioid dependence and pain since the late 1970s [1]. Published experiences from the United States, comparing buprenorphine with methadone for the treatment of pain and opioid dependence, illustrate the usefulness of buprenorphine in comparing to methadone [2-4]. Johnson, Jaffe, and Fudala explained that $8 \mathrm{mg}$ of buprenorphine per day was comparable to $60 \mathrm{mg}$ of methadone considering opiate negative urine and retention rate [5].

Sublingual buprenorphine is well absorbed; reaching 60\%-70\% of the plasma concentration, but less than $10 \%$ is absorbed when administered orally. Buprenorphine is a partial mu agonist and has ceiling, so its use has low physical dependence and less possibility of overdose. Buprenorphine decreases the incidence of HIV and other complications coming after opioid abuse. Buprenorphine detoxification is easier than methadone $[1,6-8)$.

Derivatives of opium have been used for a long time for medical, recreational and social purposes in some regions of the world, such as Asia, North America and Europe [9,10].

Currently, mental and physical problems are developing universally. In mental diseases, substance joined disorders, especially stimulants and opioids induced diseases have been considered as advancing dilemma.

Nowadays, substance related psychiatric disturbances are raising problems and have caused more referrals to outpatient and inpatient centers and hospitals [11-39].

Methamphetamine produces a common and ordinary state of well-being accompanied by raised energy, physical activity and wakefulness [8]. Prolonged use often ends to driven drug abuse, longterm health consequences, severe dependency, decreased weight, memory deficits, unstable affect, deregulated mood, increased aggression, poor concentration, increased violence, hallucinations, delusions, and poor impulse control [40,41].

Methamphetamine is abused globally. In the United States, 18 million people over age 12 have tried methamphetamine during their life [40]. As with any abused substance, meth addiction is a chronic relapsing disorder meriting the need for effective pharmacotherapies to aid the prevention of relapse.

FDA (Food and Drug Administration) accepted buprenorphine for the management of pain, as well as opioids withdrawal symptoms [8].

In the present study we are administering a single dose of $52 \mathrm{mg}$ of buprenorphine for the fast treatment of anxiety, depression, pain and craving related to methamphetamine abuse.

We could not find published reports on this subject; hence this experience may result to a new conclusion.

\section{Patient portray}

We picture a patient with the diagnosis of methamphetamine related anxiety and depressive disorder who practically answered to a single dose of $52 \mathrm{mg}$ of buprenorphine.

Our patient was a single 23 year old unemployed with high school education. He lived with his father in Shiraz city of Fars province in southern Iran. 
He began smoking tobacco at age of 18 . Then, 3 months later began smoking hashish and 4 months later started smoking of opium.

Since 1.5 years prior to admission he started smoking heroin. $\mathrm{He}$ had been heavy smoker of methamphetamine since 6 months prior to admission.

He had been occasionally abusing tramadol, methadone and benzodiazepines since 2 years prior to hospitalization.

Ten days before hospitalization he was referred to an addiction campus and was there until a couple of days ago.

At the time of admission he was very irritable, anxious, hopeless, depressed and experiencing auditory hallucination. Also he was experiencing severe chest pain and craving for methamphetamine.

Due to severe psychogenic chest pain (without any medical cause), irritability, depression, anxiety, and restlessness he was admitted in psychiatric ward.

During meticulous psychiatric interview and mental status examination he had depressed mood, agitation and insomnia. In detailed physical and neurological examinations we could not find, any significant abnormal findings.

Tests of serology for viral markers (HIV, HCV and HB Ag) were normal.

Urine drug screening tests were negative (because he was in addiction campus for 10 days prior to admission).

Based on the detailed medical, psychiatric, and substance use history and DSM-5 criteria he was diagnosed as methamphetamine related anxiety and depressive disorders.

In the first day of admission we administered venlafaxine $225 \mathrm{mg}$ and trazodone $100 \mathrm{mg}$ per day for the treatment of depression and anxiety. Because of presence of methamphetamine related disorders (craving, irritability, severe chest pain, anxiety and depression) a single dose of $52 \mathrm{mg}$ of sublingual buprenorphine was administered in the second day.

Before administration of buprenorphine, he was experiencing severe chest pain, anxiety, depression, suicidal thoughts and methamphetamine craving. Few hours after administration of a single dose of $52 \mathrm{mg}$ of buprenorphine only, he reported a fast declining level of irritability, anxiety, depression, chest pain and methamphetamine craving.

Based on the comprehensive interview, close monitoring and precise measurement ( 3 times a day), he experienced a substantial daily descending level of chest pain methamphetamine craving, anxiety and depression after receiving $52 \mathrm{mg}$ of buprenorphine.

He was discharged without any significant pain, craving or psychiatric symptoms after 2 weeks of hospitalization.

\section{Discussion}

This study indicates that buprenorphine, as a single high dose is quite effective in the rapid lowering of anxiety, depression, and chest pain and methamphetamine withdrawal symptoms. Therefore, our finding could add substantial data to the literature.

\section{Conclusions}

It looks that a single dose of buprenorphine could rapidly subside methamphetamine induced anxiety, depression, psychogenic pain and withdrawal symptoms.

It appears that buprenorphine may be a safe and valuable drug for the treatment of the majority of methamphetamine associated disorders.

\section{References}

1. Jasinski DR, Pevnick JS, Griffith JD (1978) Human pharmacology and abuse potential of the analgesic buprenorphine: a potential agent for treating narcotic addiction. Archives of General Psychiatry 35: 501-516.

2. Ling W, Charuvastra C, Collins JF, Batki S, Brown LS Jr, et al. (1998) Buprenorphine maintenance treatment of opiate dependence: a multicenter, randomized clinical trial. Addiction 93: 475-486.

3. Ling W, Rawson RA, Compton MA (1994) Substitution pharmacotherapies for opioid addiction: from methadone to LAAM and buprenorphine. J Psychoactive Drugs 26: 119-128.

4. Strain EC, Stitzer ML, Liebson IA, Bigelow GE (1994) Comparison of buprenorphine and methadone in the treatment of opioid dependence. Am J Psychiatry 151: 1025-1030.

5. Johnson RE, Jaffe JH, Fudala PJ (1992) A controlled trial of buprenorphine treatment for opioid dependence. JAMA 267: 2750-2755.

6. Lewis JW (1985) Buprenorphine. Drug and Alcohol Dependence 14: 363372.

7. Jasinski DR, Fudala PJ, Johnson RE (1989) Sublingual versus subcutaneous buprenorphine in opiate abusers. Clin Pharmacol Ther 45: 513-519.

8. Sadock, B., Sadock, V., Ruiz, P (2015) (Editors) Kaplan \& Sadock'S Synopsis of Psychiatry: Lippinott Wiliams and Wilkins, Philadelphia (USA).

9. Brian J (1994) Opium and infant-sedation in $19^{\text {th }}$ century England. Health Visit 76: $165-166$.

10. Jonnes J (1995) The rise of the modern addict. Am J Public Health 85: $1157-$ 1162.

11. Khademalhosseini Z, Ahmadi J, Khademalhosseini M (2015) Prevalence of Smoking, and its Relationship with Depression, and Anxiety in a Sample of Iranian High School Students. Enliven: Pharmacovigil Drug Saf 1: 001-005

12. Mackay-Smith M, Ahmadi J, Pridmore S (2015) Suicide In Shooting Galleries. ASEAN J Psychiatry 16: 50-56.

13. Ahmadi J, Ahmadi N, Soltani F, Bayat F (2014) Gender differences in depression scores of Iranian and German medical students. Iran J Psychiatry Behav Sci 8: 70-73.

14. Ahmadi J, Ghafoori F, Rahimi S (2015) Management of heroin addiction with baclofen and clonidine. Int J Res Rep 1: 6-10.

15. Ahmadi J, Sahraian A, Shariati S (2015) Homicidal patient with major depressive disorder companion with opium dependence: A new arcade. Int $J$ Res Rep 1: 1-5.

16. Ahmadi J (2015) Heroin Dependency Treatment: A New Approach. J Addict Depend 1: 1-3.

17. Ahmadi J (2015) Hashish-Induced Olfactory Hallucination: A Novel Finding. J Psychiatry 18: 330.

18. Ahmadi J (2015) Excellent Outcome of Psychosis Induced by Methamphetamine Intoxication after 20 Sessions of Electro Convulsive Therapy. J Addict Depend 1: 1- 2.

19. Ahmadi J, Ekramzadeh S, Pridmore S (2015) Remission of Methamphetamine- 
Induced Withdrawal Delirium and Craving after Electroconvulsive Therapy. Iran J Psychiatry Behav Sci 9: e1793.

20. Ahmadi J, Sahraian A, Dastgheib SA, Moghimi E, Bazrafshan A (2015) Treatment of heroin abuse. Sch. Acad. J. Biosci 3: 966-968.

21. Ahmadi J, Sahraian A, Dastgheib SA, Mani A, Mowla A, et al. (2015) ECT and methamphetamine psychosis: IJMPS 7: 51-53.

22. Ahmadi J (2015) Tramadol Dependency Treatment: A New Approach. J Addict Med Ther Sci 2: 001-03.

23. Ahmadi J, Dehghanian I, Razeghian Jahromi L (2015) Poly substance induced psychosis Sch. J App Med Sci 3: 2693-2695.

24. Ahmadi J, Dehghanian I, Razeghian Jahromi L (2015) Substance induced disorder. Sch J App Med Sci 3: 2700-2703.

25. Ahmadi J, Pridmore S, Ekramzadeh S (2015) Successful Use Of Electro Convulsive Therapy in The Management Of Methamphetamine Induced Psychosis With Onset During Intoxication. J Addict \& Depend 1: 1-3

26. Ahmadi J (2015) The Effect of Buprenorphine and Bupropion in the Treatmen of Methamphetamine Dependency and Craving. Br J Med \& Med Res 10: 1-4

27. Ahmadi J, Sahraian A, Dastgheib SA, Mowla A, Ahmadzadeh L (2015) Management of Methamphetamine-Induced Psychosis by 8 sessions of ECT Sch J App.Med Sci 3: 1565-1566.

28. Ahmadi J, Benrazavi L (2002) Substance use among Iranian physical patients. The International Journal of Drug Policy 13: 505-506

29. Ahmadi J, Ostovan M (2002) Substance use among Iranian male students. The International Journal of Drug Policy 13: 511-512.

30. Ahmadi J (2002) Buprenorphine maintenance treatment of heroin dependence: the first experience from Iran. J Subst Abuse Treat. Apr 22: 157-159.

31. Ahmadi $J$ (2002) A controlled trial of buprenorphine treatment for opium dependence: the first experience from Iran. Drug Alcohol Depend 66: 111 114
32. Ang-Lee K, Oreskovich MR, Saxon AJ, Jaffe C, Meredith C, et al. (2006) Single dose of 24 milligrams of buprenorphine for heroin detoxification: an open-label study of five inpatients. J Psychoactive Drugs 38: 505-512.

33. Kutz I, Reznik V (2001) Rapid heroin detoxification using a single high dose of buprenorphine. J Psychoactive Drugs 33: 191-193.

34. Anvar M, Ahmadi J, Hamidian S, Ghafaripour S (2016) Female Sexual Dysfunction Among the Wives of Opioid-Dependent Males in Iran. Int J High Risk Behav Addict 5: e25435.

35. Ahmadi J, Sahraian A, Shariati S (2015) Delusional disorder joined with opium dependence. Sch J App Med Sci 3: 3387-3390.

36. Ahmadi J, Dastgheib SA, Mowla A, Ahmadzadeh L, Bazrafshan A, et al. (2016) Treatment of Methamphetamine Induced Persistent Psychosis. J Add Pre Med 1: 103.

37. Ahmadi J, Khoddaman AR, Kordian S, Pridmore S (2016) Treatment of an obese opioid dependent with a single dose of $80 \mathrm{mg}$ of buprenorphine: a new opening. Int J Res Rep 2: 11-18.

38. Ahmadi J, Ahmadi F, Torabi A, Ahmadi S, Ahmadi F (2016) A single dose of $55 \mathrm{mg}$ of buprenorphine for the treatment of heroin dependence: a new result. J Haminiz Med Res and HIth Sci 3: $1-7$.

39. Ahmadi J (2016) Methylphenidate in the treatment of methamphetamine withdrawal craving: a novel outcome. J Drug Abuse 2: 1: 12

40. Hoffman WF, Moore M, Templin R, McFarland B, Hitzemann RJ, et al. (2006) Neuropsychological function and delay discounting in methamphetaminedependent individuals. Psychopharmacology (Berl) 188: 162-170.

41. Salo R, Nordahl TE, Natsuaki Y, Leamon MH, Galloway GP, et al. (2007) Attentional control and brain metabolite levels in methamphetamine abusers. Biol Psychiatry 61: 1272-1280.

Copyright: (c) 2016 Ahmadi J. This is an open-access article distributed under the terms of the Creative Commons Attribution License, which permits unrestricted use, distribution, and reproduction in any medium, provided the original author and source are credited. 